\title{
Research on the Application of Enterprise Competition Relationships based on Complex Network Optimization
}

\author{
Wang zhikun ${ }^{1, a}$ \\ ${ }^{1}$ Yunnan Open University \\ awangzhikun1014@163.com
}

Keywords: financial enterprise; competitive relationship; complex network; co-occurrence analysis

\begin{abstract}
Formation and evolution of enterprises' competitive relationship are not independent with each other, so that enterprises have complex relationship such as mutual initiation, interference and transformation. This complex relationship appears as complex network relation. In order to study competitive relationship between enterprises, this paper selects some financial enterprises as samples and studies financial enterprise's business type, business scale and structure property of network model, so as to study competitive relationship between financial enterprises.
\end{abstract}

\section{Introduction}

At present, domestic financial enterprises have uneven development, namely, large and medium-sized foreign enterprises and joint ventures with advanced technology provide high-level service and comprehensive financial management service for customers, while small private enterprises have poor technical equipment and backward management. With development of international economic integration, the market has higher requirements for financial enterprises. The following problems need to be urgently settled: how to regulate healthy development of China's financial market, how to adopt intensive and large-scale development way, and how to improve international competitiveness of financial enterprises.

\section{Definition of Competitive Relations between Financial Enterprises}

In researching financial enterprise's competitive relationship, niche overlap is an important concept to describe competitive relations between enterprises. Competitive relationship will appear when enterprises target at same market or customer. Niche overlap shows that two enterprises have mutual substitution effect in the market, so that their performance competition is mutual. Belonging to circulation service industry, financial enterprise provides products which serve finance and have characteristics of spatial distribution. Competitions between enterprises are mainly reflected in competitions of provided service's business types and operation regional scope. If enterprises target at same market or customer in business types and regional scope, so that enterprises will have competitive relationship. In addition, due to different locations of different enterprises, competitions will show different degrees of intensity, and competition between enterprises in same area will be more intense than that between enterprises located in adjacent regions. This article defines competitive relationship between enterprises from two aspects of financial enterprise located in the same region and adjacent areas.

\section{Sample Selection of Financial Relationship and Explanation of Computation Example}

Figure 1 is flow chart which describes construction process of network model in competitive relationship between financial enterprises in Kunming. ${ }^{e_{i j}}$ represents edge connecting two financial enterprises: when $e_{i j}=0$, enterprise $\mathrm{i}$ and enterprise $\mathrm{j}$ have no competitive relationship; when $e_{i j}=\mathrm{X}$, enterprise $\mathrm{i}$ and enterprise $\mathrm{j}$ have competitive relationship. In BCRN model, the value of $\mathrm{X}$ is 1 ; in WCRN model, the value of $\mathrm{X}$ is edge weight, which is calculated according to formula (1). Taking 
financial enterprise with node of no. 1 in 2009 as an example, table 2 provides basic information of financial enterprises.

Step1: Determine whether two enterprises have same business type, if they have no same business type, $e_{i j}=0$; otherwise, move on to step2.

Step2: Classify financial enterprises by turnover referring to transportation enterprise's classification standard in national Interim Provisions on Standards for Medium and Small Enterprises.

Step3: according to enterprise's latitude and longitude, calculate straight-line distance between enterprises by converting Gauss projection.

Step4: Determine whether two financial enterprises are small enterprises. If both of them are small and medium enterprises with straight-line distance of less than $15 \mathrm{~km}, e_{i j}=X$; otherwise, $e_{i j}=0$.

Step5: Calculate shortest distance between enterprises connected by road network using Floyd algorithm.

Step6: (1) Determine whether two enterprises are not large enterprises. That is, two enterprises are medium-sized enterprises, or one of them is a medium-sized enterprises, and another is small businesses; (2) If two enterprises are not large enterprises with straight-line distance of less than 30 $\mathrm{km}, e_{i j}=X$, otherwise; (3) Determine whether distance between two enterprises along road network is less than 50 kilometers. If distance is less than 50 kilometers, $e_{i j}=X$,otherwise $e_{i j}=0$.

Step7: (1) Determine whether one of the two enterprises is a large enterprise; (2) If there is a large enterprise, and straight-line distance between two enterprises is less than 45 kilometers, $e_{i j}=X$,otherwise; (3) Determine whether distance along the road is less than $100 \mathrm{~km}$, if distance is less than 100 kilometers, $e_{i j}=X$, otherwise $e^{e_{i j}}=0$.

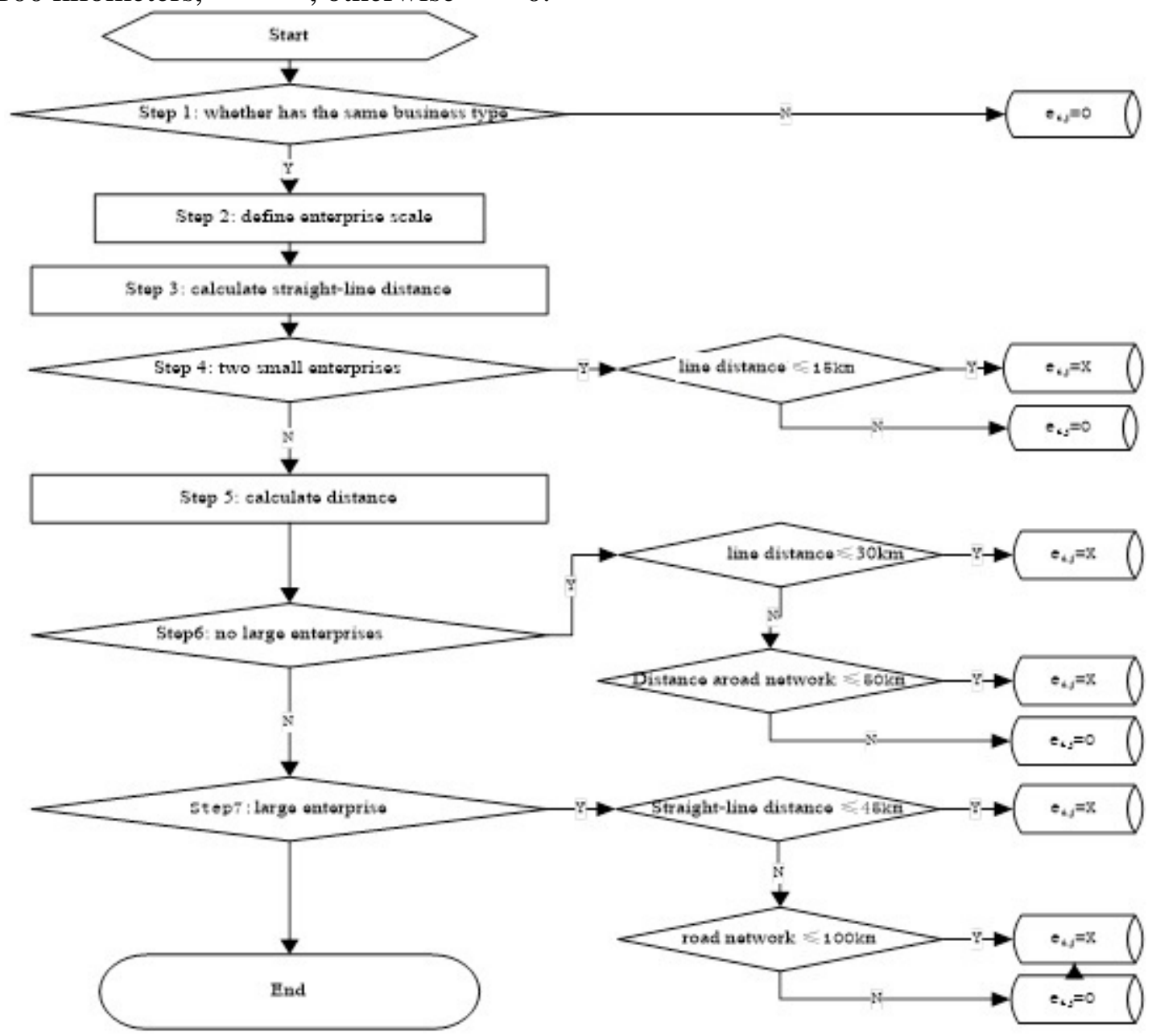


Table 1 Basic Information of Financial Enterprise

\begin{tabular}{c|c|c|c|c|c|c}
\hline \multirow{2}{*}{ Node no. Of enterprise } & \multirow{2}{*}{\begin{tabular}{c} 
Enterprise type \\
\multirow{2}{*}{1}
\end{tabular}} & \multicolumn{2}{|c|}{ Location } & \multicolumn{3}{c}{ Turnover(10,000 yuan) } \\
\hline \multirow{2}{*}{$\begin{array}{c}\text { Medium } \\
\text { enterprise }\end{array}$} & Longitude & Latitude & Storage & Transportation & $\begin{array}{c}\text { Freight } \\
\text { forwarding }\end{array}$ \\
\cline { 3 - 7 } & & 113.8341 & 23.0314 & 874.36 & 15893.01 & 8720.53 \\
\hline
\end{tabular}

With financial enterprise as the node, if two enterprises have same business type in one business or several businesses in same area or adjacent areas, one edge will be connected between two enterprises, so as to build Boolean Competitive Relationship Network of financial enterprises (BCRN). Collection of BCRN is expressed as $G=(F, A), F$ refers to collection of financial enterprises and represents financial enterprises, and A refers to adjacent matrix of competitive relationship between financial enterprises, and matrix elements are assigned by formula (1).

$$
a_{i j}=\left\{\begin{array}{l}
0, \text { set }_{i} \bigcap \text { set }_{j}=\phi \\
1, \text { set }_{i} \bigcap \text { set }_{j} \neq \phi
\end{array}\right\}
$$

In (1) equation, ${ }^{s e t_{i}}$ refers to financial enterprises in same region or neighboring regions provide collection of business types. The equation shows that financial enterprises in same region or neighboring regions with at least one same business type have competitive relationship.

\section{Conclusion}

With financial industry in Kunming as research sample, this paper studies evolution characteristics of financial enterprises' competitive relationship by using complex network method. According to this paper's research, Boolean network node degree of financial enterprises' competitive relationship is subordinated to distribution without standard, and network topology structure has small world. Through analyzing network model of financial enterprises' competitive relationship, this paper has found that in financial industry, most financial enterprise are facing many ubiquitous competitors; as time changes, competition between financial enterprises has become more and more fierce; few key enterprises occupy most of the market share and will play important role in development of financial market; from the perspective of evolution, enterprises with rapid growth mainly are engaged in transportation and freight forwarding business; in recent years, financial industry has strengthened dispersion, and small-medium enterprises have developed rapidly.

\section{References}

[1] Wang Yunan. Research on Market Structure and Competition Strategy of Third-party Finance in China[D]. Dalian: Dalian Maritime University, 2004

[2]Y. Geng, J. Chen, K. Pahlavan, Motion detection using RF signals for the first responder in emergency operations: A PHASER project, 2013 IEEE 24nd International Symposium on Personal Indoor and Mobile Radio Communications (PIMRC), London,Britain Sep. 2013

[3] Hou Rui, Yang Jianmei, Yao Canzhong. Research on Complex Network of Financial Enterprises' Competitive Relationship[J]. Journal of Management, 2010, 7(3): 406-411

[5]Y. Geng, J. He, K. Pahlavan, Modeling the Effect of Human Body on TOA Based Indoor Human Tracking[J], International Journal of Wireless Information Networks 20(4), 306-317 